\title{
ARTÍCULOS
}

\section{EL CONTROL NAVAL ALIADO ENTRE CANARIAS Y LA PENÍNSULA DURANTE LA SEGUNDA GUERRA MUNDIAL (SEPTIEMBRE DE 1939-JUNIO DE 1940)}

\section{The allied naval control between the Canary Islands and the Iberian Peninsula during the Second World War (september 1939-june 1940)}

\author{
Teodoro Fidel Santana Nelson \\ Universidad de Las Palmas de Gran Canaria \\ teodoro.nelson@ulpgc.es \\ Orcid: 0000-0002-2852-3482 \\ Juan José Díaz Benítez \\ Universidad de Las Palmas de Gran Canaria \\ juanjose.diaz@ulpgc.es \\ Orcid: 0000-0002-3563-1326
}

Cómo citar este artículo/Citation:

Teodoro Fidel Santana Nelson y Juan José Díaz Benítez, "El control naval aliado entre Canarias y la Península durante la Segunda Guerra Mundial (septiembre de 1939junio de 1940)", Hispania Nova, 19 (2021): 166 a 195.

DOI: https://doi.org/10.20318/hn.2021.5879
Copyright: (C) HISPANIA NOVA es una revista debidamente registrada, con ISSN 1138-7319 y Depósito Legal M 9472-1998. Los textos publicados están -si no se indica lo contrario- bajo una licencia Reconocimiento-Sin obras derivadas 3.0 España de Creative Commons. Puede copiarlos, distribuirlos y comunicarlos públicamente siempre que cite su autor y la revista y la institución que los publica y no haga con ellos obras derivadas. La licencia completa se puede consultar en: http://creativecommons.org/licenses/by-nd/3.0/es/deed.es
Resumen: En este artículo analizaremos las detenciones llevadas a cabo por los Aliados en la zona atlántica de Canarias, cómo y por qué se llevaban a cabo y qué suponían dichas detenciones en las relaciones anglo-españolas.

Palabras clave: Detenciones navales, Segunda Guerra Mundial, Bloqueo, Neutrales, España, Reino Unido.
Abstract: In this article we are going to analyse the ships's arrest carried out by the allies in the Atlantic area of the Canary Islands, how and why these detentions were carried out and what the arrest in anglo-spanish relations entail.

Keywords: Naval Detentions, Second World War, Spain, Neutrals, United Kingdom, Spain. 


\section{INTRODUCCIÓN ${ }^{1}$}

La política exterior española ha sido objeto de debate e incluso polémica desde los años de la contienda, cuando Estados Unidos y Gran Bretaña exigían al Gobierno español el cumplimiento de sus obligaciones como neutral. Desde entonces se fue desarrollando un discurso oficial que insistía en la voluntad española de evitar su entrada en la guerra, patente en los libros de Ramón Serrano Suñer, ministro de Asuntos Exteriores entre 1940 y 1942, y José María Doussinague, director general de Política Exterior del Ministerio de Asuntos Exteriores, y continuado en la historiografía por autores como Luis Suárez Fernández, entre otros ${ }^{2}$. Frente a esta interpretación justificadora de la política exterior española, poco a poco se fue abriendo paso una interpretación crítica, con aportaciones como la de Víctor Morales Lezcano, que definió la no beligerancia española como una pre-beligerancia a favor del Eje, ampliada por Javier Tusell a partir de las fuentes diplomáticas españolas ${ }^{3}$. Muchas han sido las contribuciones a esta interpretación crítica, desde la colaboración clandestina del Gobierno español con el Tercer Reich, estudiada por Manuel Ros Agudo y David Wingeate Pike, entre otros autores, hasta las relaciones de España con Estados Unidos, analizadas por Joan Maria Thomàs, y con Gran Bretaña ${ }^{4}$. Estas últimas han sido abordadas por numerosos investigadores que se han centrado en diferentes aspectos: entre las aportaciones más recientes destacan el despliegue de los servicios de inteligencia británicos en España, analizado por Emilio Grandío Seoane, la operación de soborno de la cúpula militar española, estudiada por Ángel Viñas, y una visión de

\footnotetext{
${ }^{1}$ Este artículo recoge parte de los resultados del proyecto TESIS2018010017, financiado por la Agencia Canaria de Investigación, Innovación y Sociedad de la Información, y del proyecto de investigación HAR2017-87441-P, financiado por el Ministerio de Ciencia, Innovación y Universidades.

${ }^{2}$ Ramón Serrano Suñer, Entre Hendaya y Gibraltar (Madrid: Ediciones y Publicaciones Españolas, 1947). José María Doussinague, España tenía razón (Madrid: Espasa Calpe, 1949). Luis Suárez Fernández, España, Franco y la Segunda Guerra Mundial (Madrid: Editorial Actas, 1997).

${ }^{3}$ Víctor Morales Lezcano, Historia de la no beligerancia española durante la Segunda Guerra Mundial (Las Palmas de Gran Canaria: Mancomunidad de Cabildos de Las Palmas, 1980). Javier Tusell, Franco, España y la Segunda Guerra Mundial (Madrid: Ediciones Temas de Hoy, 1995).

${ }^{4}$ Manuel Ros Agudo, La guerra secreta de Franco (1939-1945) (Barcelona: Editorial Crítica, 2002). David Wingeate Pike, Franco y el Eje Roma-Berlín-Tokio (Madrid: Alianza Editorial, 2010). Joan Maria Thomàs, Roosevelt y Franco. De la guerra civil española a Pearl Harbor (Barcelona: Edhasa, 2007). También del último autor: La batalla del wolframio. Estados Unidos y España. De Pearl Harbor a la Guerra Fría (1941-1947) (Madrid: Ediciones Cátedra, 2010).
} 
conjunto de las relaciones hispano-británicas, tanto en lo diplomático como en lo militar y lo económico, de la mano de Enrique Moradiellos, entre otros autores ${ }^{5}$.

Sin embargo, el amplio estudio de las relaciones hispano-británicas no ha sido agotado por estos trabajos. De hecho, todavía quedan cuestiones que apenas han recibido atención por parte de los historiadores, como el control aliado sobre la navegación neutral y, más concretamente, la española. No se trata de un tema desconocido sino de un procedimiento aplicado por los Aliados, especialmente por Gran Bretaña, en las dos guerras mundiales con el fin de hacer efectivo el bloqueo económico de Alemania y sus aliados y dificultar de ese modo su esfuerzo bélico. Más allá de la discutida eficacia del bloqueo económico, la aplicación del control de la navegación no estuvo exenta de polémicas y desencuentros con los neutrales, particularmente España, dado su sospechoso acercamiento al Eje. Además, en el caso del país ibérico, y al igual que ocurría con Portugal y sus islas atlánticas, el control naval se ejercía no sólo sobre los barcos que se dirigían a puertos extranjeros sino también sobre los que mantenían las comunicaciones dentro del territorio nacional, concretamente entre la Península y Canarias. La documentación generada con respecto a la detención de buques españoles que cubrían esta ruta es abundante y constituye tanto un ejemplo de los medios de presión habituales del Gobierno británico sobre el español como la constatación casi cotidiana de la debilidad de este último frente a los abusos reales o supuestos del primero.

Un control excesivamente rígido podía tener efectos devastadores sobre el archipiélago canario, dependiente económicamente del exterior y que desde mediados de 1940 experimentó una creciente revalorización estratégica para Gran Bretaña como alternativa a Gibraltar en el caso de que, finalmente, se materializase la beligerancia de España. Por tanto, este artículo se centra en el control británico de la navegación sobre esta ruta tan vulnerable que conectaba a España con sus islas atlánticas. El marco cronológico se circunscribe a la primera fase de la Segunda Guerra Mundial, concretamente entre septiembre de 1939 y junio de 1940, antes de la firma del armisticio por Francia. Durante esos meses el control británico en Gibraltar fue

\footnotetext{
${ }^{5}$ Emilio Grandío Seoane, A Balancing Act: British Intelligence in Spain during the Second World War (Brighton: Sussex Academic Press, 2017). Ángel Viñas, Sobornos: De cómo Churchill y March compraron a los generales de Franco (Barcelona: Crítica, 2016). Enrique Moradiellos, Franco frente a Churchill: España y Gran Bretaña en la Segunda Guerra Mundial (1939-1945) (Barcelona: Ediciones Península, 2005).
} 
reforzado por el control francés desde los puertos marroquíes, mientras que la guerra naval alemana contra el tráfico marítimo aliado era ejercida desde bases situadas en Alemania y con unas fuerzas navales inicialmente reducidas, por lo que su impacto fue mucho menor que en el periodo 1940-42. También estos meses iniciales coinciden con la declaración oficial española de neutralidad, antes de la no beligerancia proclamada en junio de 1940, aunque ya en la primera fase de la guerra se percibía una actitud favorable al Tercer Reich y, de hecho, desde finales de noviembre de 1940, había comenzado la colaboración clandestina con el esfuerzo naval alemán, lo que suponía el incumplimiento por parte del Gobierno español de una serie de obligaciones como neutral. Igualmente, no debemos olvidar cómo el gobierno británico tuvo una actitud "permisiva" ${ }^{6}$ respecto a los rebeldes franquistas durante la Guerra Civil. De hecho, a partir de 1938 la inteligencia española pasó de centrarse en neutralizar a los republicanos para pasar a vigilar el espionaje inglés, las instalaciones del Peñón o la opinión pública de los gibraltareños. A finales de 1937 los servicios de inteligencia alemanes, italianos y españoles habían recopilado cuantiosa información sobre Gibraltar (depósitos, baterías, antenas de comunicación...) como previsión a un plan de ataque futuro. El propio gobierno franquista preparó un plan que incluía el despliegue de varias baterías de artillería para reconquistar el Peñón si las circunstancias internacionales lo permitieran. Toda esta situación influiría en la actuación inglesa en la zona. No debemos menospreciar el papel que Gibraltar jugó en la Guerra Civil ${ }^{7}$. Esta situación también permite entender la no ruptura total de las relaciones anglo-españolas y las contradicciones inherentes con las que las autoridades inglesas se encontrarían al momento de la guerra.

El estudio de los conflictos generados por el control de la navegación entre los dos países requiere inexcusablemente la consulta de fuentes primarias que reflejen ambos puntos de vista. Para la perspectiva británica se ha analizado la documentación custodiada en The National Archives (TNA), dentro de la cual destacan tres fondos especialmente significativos para esta investigación: la correspondencia de la Colonial Office (Secretaría de Colonias); los archivos del Admiralty (Almirantazgo); y la

\footnotetext{
${ }^{6}$ Julio Ponce Alberca. "Espionaje en Gibraltar y su Campo (1936-1945)" en Revista Universitaria de Historia Militar, (2015) pp. 35-54.

${ }^{7}$ Julio Ponce Alberca. "La Guerra Civil y el Peñón de Gibraltar” en Historia Contemporánea, 41 (2010) pp. 23.
} 
documentación del Foreign Office (Secretaría de Asuntos Exteriores), especialmente la relativa al Political Department (Departamento de Política) y al Ministry of Economic Warfare o MEW (Ministerio de Guerra Económica) ${ }^{8}$. Por parte española, se ha recurrido a la documentación diplomática conservada en dos archivos. En primer lugar, el Archivo General de la Administración (AGA), cuya sección de Asuntos Exteriores ha sido vital para esta investigación. En segundo lugar, el Archivo General del Ministerio de Asuntos Exteriores (AMAE), cuyo Archivo Renovado, actualmente en el AGA, ha completado la información del fondo anterior. A todo ello hay que añadir otros fondos documentales de estos y otros archivos, consultados de forma puntual para completar la información.

El análisis de estas fuentes ha permitido confirmar la hipótesis de partida: el Gobierno español se encontró en una situación de debilidad frente a un sistema de control aliado de la navegación cada vez más duro y conflictivo. Esta dureza respondía en parte a la propia actitud de España frente a los beligerantes y especialmente a su colaboración con el Tercer Reich, de la cual sospechaban Francia y Gran Bretaña, por lo que el primer apartado de este artículo aborda esta cuestión. El segundo analiza cómo se estableció dicho control naval, sobre todo en el Atlántico oriental y las modificaciones que experimentó hasta junio de 1940. El tercero está dedicado a las situaciones conflictivas que fueron surgiendo durante la aplicación del control naval, así como su desenlace, que puso de manifiesto una y otra vez el limitado margen de maniobra de la diplomacia española.

\section{LA NEUTRALIDAD ESPAÑOLA}

El control de la navegación no se aplicaba exclusivamente a España. Al contrario, la persecución del contrabando de guerra incluía a todos los neutrales, tal y como se puede apreciar en las listas de empresas y particulares acusados de comerciar con el Tercer Reich ${ }^{9}$. Igualmente, no faltaron momentos de tensión entre Gran Bretaña y

\footnotetext{
${ }^{8}$ Con el fin de facilitar la localización de la documentación, en las correspondientes notas a pie de página se conservará las referencias en inglés.

${ }^{9}$ Despacho núm. 92 de la Embajada de España en Londres al Ministerio de Asuntos Exteriores, 14 de febrero de 1941, adjuntando una copia de The Trading with the Enemy (Specified Persons) (Amendment)
} 
los neutrales. El tráfico marítimo portugués con Azores y Madeira estaba sujeto a los mismos controles que el español con Canarias, lo cual no impidió que Portugal se convirtiera en uno de los principales proveedores de wolframio para Alemania ${ }^{10}$. Entre marzo de 1940 y mayo de 1945 los Aliados y Alemania controlaron el comercio marítimo de Suecia a través del "tráfico de salvoconducto", utilizado por ambos para presionar al país escandinavo. Un episodio particularmente tenso fue la detención de cuatro destructores suecos, adquiridos de segunda mano a Italia, por la Royal Navy el 20 de junio de $1940^{11}$. Las importaciones de materias primas de Suiza también dependían del consentimiento de ambos beligerantes, que usaron esta dependencia para presionar al país helvético ${ }^{12}$. La neutralidad de Irlanda, demasiado estricta en opinión de Gran Bretaña y otros países de la Commonwealth, no fue incompatible con una gran dependencia comercial y financiera con respecto a la economía británica ${ }^{13}$. Durante la primera fase de la guerra Gran Bretaña se convirtió en el principal socio comercial de Turquía, pero a partir de octubre de 1941 esta última exportó cromo en grandes cantidades al Tercer Reich hasta que la presión de los Aliados acabó con este comercio en abril de $1944^{14}$.

Sin embargo, lo que distingue a España de los demás neutrales europeos es que fue el único que intentó entrar en la guerra al lado del Eje. Frente al discurso oficial, según el cual el Gobierno español nunca quiso la beligerancia, los historiadores han construido una interpretación más compleja que muestra la adaptación de la política exterior española al desarrollo de la Segunda Guerra Mundial. A pesar de los lazos diplomáticos, económicos y militares que ataban al régimen de Franco al Tercer Reich e Italia desde la Guerra Civil, España no estaba en condiciones de entrar en la guerra en

(n. 2) Order, 1941, dated February 4, 1941, made by the Board of Trade, Archivo General de la Administración (AGA), Asuntos Exteriores, caja 7.289.

${ }^{10}$ Fernando Rosas, "Portuguese neutrality in the Second World War", en European neutrals and nonbelligerents during the Second World War, ed. por Neville Wylie (Cambridge: Cambridge University Press, 2002), 268-282.

11 John Gilmour, Sweden, the Swastika and Stalin. The Swedish Experience in the Second World War (Edinburgh: Edinburgh University Press, 2011), 57-58 y 215.

12 Neville Wylie, Britain, Switzerland and the Second World War (Oxford: Oxford University Press, 2003), 176-181. Christian Leitz, Nazi Germany and Neutral Europe during the Second World War (Manchester: Manchester University Press, 2000), 26-40.

13 Eunan O'Halpin, "Irish Neutrality in the Second World War", en European neutrals and nonbelligerents during the Second World War, ed. por Neville Wylie (Cambridge: Cambridge University Press, 2002), 283-303.

${ }^{14}$ Christian Leitz, Nazi Germany and..., 87-89 y 101-107. 
septiembre de 1939, por lo que se declaró neutral. Las victorias alemanas en la primavera de 1940 abrieron la puerta a la declaración de no beligerancia española y al ofrecimiento de la beligerancia en junio de 1940, negociada infructuosamente en el otoño de ese año. A pesar del aplazamiento de la entrada en la guerra, ante la ausencia de garantías alemanas para las reivindicaciones territoriales españolas, el inicio de la operación Barbarroja marcó el comienzo de la llamada "beligerancia moral", hasta que el relevo de Serrano Suñer por Gómez-Jordana a partir de agosto de 1942 marcó el comienzo del incompleto retorno a una política de estricta neutralidad, forzada por una creciente presión aliada, especialmente desde mediados de $1943^{15}$.

De estas etapas, la más significativa para este artículo es la primera, en la que la neutralidad oficial, forzada por la incapacidad para entrar en la guerra, no se correspondía con las aspiraciones del nuevo régimen ni con algunas de sus acciones, impropias de un país neutral. El acercamiento al Eje había comenzado durante la Guerra Civil, cuando la ayuda alemana e italiana fue decisiva para que los sublevados contra el gobierno republicano lograran imponerse. Su coste se tradujo en la reorientación del comercio español hacia estos países, que desplazaron así a Francia y Gran Bretaña, y el pago de una onerosa deuda de guerra ${ }^{16}$. Los tratados secretos de amistad firmados con ambos países poco después de terminar la Guerra Civil alinearon a España con el Eje ${ }^{17}$, del cual esperaba ayuda para una redistribución colonial más justa. Esta cuestión ya fue planteada en el anteproyecto de flota de junio de 1938, en el que el futuro programa de construcciones navales estaba diseñado para participar en una guerra al lado de Alemania e Italia contra Francia y Gran Bretaña, cuyo desenlace se traduciría en una sustancial ampliación de las posesiones españolas en el noroeste de África ${ }^{18}$.

Los preparativos bélicos españoles en 1939 incluyeron, como ya mencionamos, una operación para conquistar Gibraltar, pero los ambiciosos programas de rearme aprobados poco después del inicio de la Segunda Guerra Mundial confirmaban que

\footnotetext{
${ }^{15}$ Elena Hernández Sandoica y Enrique Moradiellos, "Spain and the Second World War, 1939-1945", en European neutrals and non-belligerents during the Second World War, ed. por Neville Wylie (Cambridge: Cambridge University Press, 2002), 241-267.

${ }^{16}$ Rafael García Pérez, Franquismo y Tercer Reich: las relaciones económicas hispano-alemanas durante la Segunda Guerra Mundial (Madrid: Centro de Estudios Constitucionales, 1994), 45-89. Jordi Catalan, La economía española y la segunda guerra mundial (Barcelona, Editorial Ariel, 1995), 209-213.

${ }^{17}$ Ros Agudo, La guerra secreta..., 28-34.

18 Juan José Díaz Benítez, "El anteproyecto de flota de 1938 y la no beligerancia española durante la Segunda Guerra Mundial”, Ayer. Revista de Historia Contemporánea, núm. 49 (2003): 271-289.
} 
España necesitaría al menos una década para construir las fuerzas armadas adecuadas para desafiar a Francia y Gran Bretaña. Además, necesitaría ayuda de la tecnología alemana e italiana, especialmente en la construcción de una gran flota de guerra, pero la realidad no se correspondió con estas expectativas ${ }^{19}$. La falta de apoyo tecnológico del Eje se combinó con las necesidades más apremiantes de reconstrucción del país después de la Guerra Civil. A pesar de que las destrucciones ocasionadas por la contienda no fueron mucho mayores que las padecidas por otros países europeos durante la Segunda Guerra Mundial y sobre todo bajo la ocupación alemana ${ }^{20}$, España necesitaba importar combustible para mantener en funcionamiento su economía y grano para alimentar a gran parte de su población. Sin divisas para pagar estas y otras importaciones vitales y con unas comunicaciones marítimas controladas por Francia y Gran Bretaña, el nuevo régimen español se veía obligado a depender de los créditos y los permisos franceses y británicos para aliviar su precaria situación económica ${ }^{21}$. Esta dependencia externa contribuyó a que el Gobierno español se declarase inicialmente neutral.

No obstante, esto no implicó una equidistancia con respecto a Alemania y los Aliados ni un escrupuloso cumplimiento de todas sus obligaciones como neutral. Además de la evidente germanofilia que mostraba la prensa española ${ }^{22}$, había otras formas de colaboración más discretas e interesantes para el Tercer Reich, sobre todo para su guerra naval contra el tráfico británico y francés. Uno de sus mayores inconvenientes consistía en la ausencia de bases navales que permitieran la acción de los submarinos y los buques de guerra de superficie lejos de Europa, así como mantenerse de forma prolongada en la zona de operaciones. La respuesta a este problema consistió en el Etappendienst o Etappenorganisation, un servicio de apoyo logístico desplegado en países neutrales, desmantelado tras la Primera Guerra Mundial y reconstruido a partir de la década de 1930. España y Portugal constituían una de las grandes etapas de este servicio de apoyo logístico, dirigida por el capitán de fragata Kurt Meyer Döhner, agregado naval alemán en España. A pesar de su reticencia inicial, ya que las actividades de este servicio suponían un claro incumplimiento del XIII Convenio Internacional de La Haya (1907) al usar el territorio neutral como base de operaciones,

\footnotetext{
${ }^{19}$ Ros Agudo, La guerra secreta..., 34-71

${ }^{20}$ Catalan, La economía española y..., 41-59.

${ }^{21}$ Viñas, Sobornos, 32-42.

${ }^{22}$ Pike, Franco y el Eje..., 64-70 y 76-82.
} 
Franco dio su consentimiento verbal a finales de noviembre de 1939, haciendo posible así la actuación del Etappendienst en España ${ }^{23}$.

Canarias constituía una de las zonas de la gran etapa España-Portugal, cuyos hombres de confianza (Vertrauenmänner, $V m$ ) trabajaban en los puertos de La Luz y Santa Cruz de Tenerife. El servicio había sido organizado antes de la guerra e intentó adquirir acciones de la refinería de CEPSA en Santa Cruz de Tenerife para disponer de combustible líquido en el archipiélago. Esta operación no fue culminada con éxito, pero la llegada de barcos mercantes alemanes a los puertos isleños, buscando refugio ante el riesgo de ser capturados por buques de guerra británicos o franceses, facilitó la preparación de las operaciones de abastecimiento, sobre todo con los cuatro petroleros refugiados en los principales puertos canarios: Charlotte Schliemann y Winnetou en La Luz; Rekum y Eurofeld en Santa Cruz de Tenerife. En diciembre de 1939, el Pioneer, un buque alemán que había zarpado desde la actual Guinea Ecuatorial, entonces colonia española, recibió combustible en el Puerto de la Luz en su viaje de vuelta a Alemania ${ }^{24}$. Antes de que acabara ese año, cuatro de los buques refugiados en el archipiélago, Chemnitz, Biscaya, Amasis y Asuncion, también intentaron romper el bloqueo naval aliado para llegar hasta Alemania, consiguiéndolo los dos últimos. En abril de 1940 el Winnetou zarpó del Puerto de la Luz como buque de abastecimiento del crucero auxiliar Orion, al cual proporcionó combustible en mayo y junio, antes de proseguir su viaje hasta llegar a Japón en septiembre de ese mismo año ${ }^{25}$.

Los cuatro petroleros alemanes refugiados en Canarias sumaban 21.810 toneladas de gasoil y 16.100 de fuel, pero no disponían de las indispensables provisiones para las tripulaciones de los buques de guerra. El transporte de estas provisiones en grandes cantidades a los citados puertos canarios no fue una tarea sencilla, pues el control naval aliado intentó impedirlo ${ }^{26}$. Igualmente, el abastecimiento de los submarinos que debían entrar por la noche en el Puerto de la Luz requería el uso

\footnotetext{
${ }^{23}$ Juan José Díaz Benítez, "The Spanish support for the Third Reich in the Second World War: new considerations about the Etappenorganisation", The International Journal of Maritime History 28, núm. 3 (2016): 513-531, doi: 10.1177/0843871416647347.

${ }^{24}$ Juan José Díaz Benítez, "The Etappe Kanaren: A case study about the secret supply of the German Navy in Spain during the Second World War", The International Journal of Maritime History 30, núm. 3 (2018): 472-487, doi: 10.1080/00253359.2018.1487676.

${ }^{25}$ Juan José Díaz Benítez, "German supply ships and blockade runners from the Canary Islands in the Second World War", The Mariner's Mirror 104, núm. 3 (2018): 318-329, doi: 10.1080/00253359.2018.1487676.

${ }^{26}$ Juan José Díaz Benítez, “The Etappe Kanaren...”, 477-480.
} 
de un barco menos llamativo que los petroleros. Con esta finalidad, el vapor mercante Corrientes fue modificado en noviembre de 1939 por la compañía Depósito de Carbones de Tenerife, convirtiéndose en un buque de abastecimiento. Es posible que los servicios de inteligencia aliados sospecharan del buque, pues el 9 de mayo de 1940 sufrió un ataque, atribuido inicialmente a un disparo de cañón del mercante artillado francés Le Rhin, aunque lo más probable es que fuera realizado con minas magnéticas (limpet mines) adosadas a su casco ${ }^{27}$. El Corrientes no tardó en ser reparado, pero el incidente sugiere que los Aliados tenían dudas, no siempre fundadas, aunque sí razonables, sobre el cumplimiento de las obligaciones que la neutralidad imponía a España y, en consecuencia, el control naval aliado actuó con un celo que, desde la perspectiva del Gobierno español, podía resultar excesivo.

Igualmente, también debemos tener en cuenta la actuación de los puertos de Vigo y A Coruña como refugio para barcos y submarinos alemanes, en una posición un tanto análoga a la canaria. Si caía Gibraltar, el control de estos puertos gallegos sería fundamental para no perder el control del Atlántico ${ }^{28}$.

\section{ESTABLECIMIENTO DEL CONTROL NAVAL ALIADO}

La cooperación franco-británica para el control de la navegación se preparó ya desde mayo de $1939^{29}$. Aunque las zonas de operación fueron encargadas a un Almirantazgo u otro, en la práctica la organización fue conjunta. Las zonas de operaciones fueron modificadas varias veces de común acuerdo. El mando de algunas fuerzas navales podía cambiar de un país a otro. Estas tareas combinadas eran vitales, debido a los inmensos objetivos de ambas marinas. Al mismo tiempo que aseguraban el bloqueo, debían proteger los 23 millones de toneladas mercantes que poseían los aliados. Aunque durante la Phoney War la práctica del bloqueo aún se basaba en la Gran

\footnotetext{
${ }^{27}$ Juan José Díaz Benítez, "El ataque contra el buque alemán Corrientes en el Puerto de la Luz en mayo de 1940", en XX Coloquio de Historia Canario Americana, 1161-1170, coord. por Elena Acosta Guerrero (Las Palmas de Gran Canaria: Cabildo de Gran Canaria, 2014), http://coloquioscanariasamerica.casadecolon.com/index.php/CHCA/article/view/9242 (24/09/2020).

${ }^{28}$ Grandío Seoane, Emilio. No sólo wolframio. Galicia, campo de juego de las redes de inteligencia durante la Segunda Guerra Mundial. En Revista Universitaria de Historia Militar, (2015) pp. 101-117.

${ }^{29}$ Henri Michel, La Segunda Guerra Mundial. Tomo I. Los éxitos del Eje. $2^{\text {a }}$ Ed. (Madrid: Akal, 1990), 64.
} 
Guerra, poco a poco se fueron introduciendo nuevas medidas. Sin embargo, "debería esperarse mucho tiempo para que el bloqueo fuera eficaz" 30 .

En lo que respecta a Gran Bretaña, cabe destacar el Naval Prize Manual de 1923, vigente para esta guerra, y en especial la Reprisals Order de 1939, la cual generaría quejas por parte del Gobierno español ${ }^{31}$. En cuanto la extensión de las aguas internacionales, hay que tener en cuenta la problemática respecto a ellas que empieza a surgir desde la Conferencia de Codificación de la Haya de $1930^{32}$. El límite de las tres millas comenzaba a desdibujarse; España seguía defendiendo su límite en las seis millas.

En marzo de 1940 el vapor Plus Ultra fue detenido en alta mar. A través de este suceso podemos observar, paso a paso, cómo se efectuaban estas inspecciones navales. El Plus Ultra cumplía el servicio regular con Fernando Póo. Evidentemente, el transcurso de una inspección en alta mar podía discurrir de forma muy diversa, dependiendo, claro, de lo que encontraran (o no encontraran). Sin embargo, por lo general el proceso era similar a lo sucedido con este vapor ${ }^{33}$.

Así, el 13 de marzo de 1940, a las 17:00, Lat. N. 36² 25’00 y Long. O. $6^{\circ} 31^{\prime}$ el Plus Ultra fue detenido por el patrullero francés Clairvoyant $P-15^{34}$. Una vez el buque había parado, se le preguntó por su procedencia y destino. A continuación, el comandante del patrullero ordenó por megáfono fachear para mandar el bote, efectuando el derecho de visita. Subieron al barco un oficial con dos marineros armados (la dotación de presa). Otro quedó guardando el bote. Seguidamente, se revisó la documentación y se le inquirió las aclaraciones pertinentes. Tras consultar con su comandante, el oficial estampó una nota en el diario de navegación del vapor. A las 19:00 se le permitió seguir a Cádiz y a las 21:30 amarró finalmente en el muelle. Por

\footnotetext{
${ }^{30}$ Henri Michel, La Segunda... 65.

31 Vizcount Halifax to Señor Marques de los Arcos, 19 de enero de 1940. Colonial Office: Colonies, General: Original Correspondence (CO 323) expediente 1773 1. The National Archives (TNA). https://discovery.nationalarchives.gov.uk/details/r/C4504683 (24/09/2020).

${ }^{32}$ Víctor Luis Gutiérrez Castillo, "La evolución de la anchura del mar territorial. Perspectiva internacional y española." Ámbitos. Revista de estudios de Ciencias Sociales y Humanidades, núm. 9 (2003): 87-93 1995. https://helvia.uco.es/xmlui/bitstream/handle/10396/8586/9 7.pdf?sequence=1 (24/09/2020).

33 Sobre detención vapor español "Plus Ultra", 19 de marzo de 1940, AGA, Asuntos Exteriores, caja 11338.

${ }^{34}$ Curiosamente, en una nota posterior de Lequerica se dice que debió tratarse de un destructor inglés, según el Ministerio de Bloqueo. Al Ministerio de Asuntos Exteriores, 18 de marzo de 1940, AGA, Asuntos Exteriores, caja 11338.
} 
supuesto, fue muy común desviar directamente estos buques a Gibraltar. Y fue obligatorio a partir de mayo de 1940: “[...] Todos los barcos, tanto españoles como extranjeros que pasen el Estrecho y conduzcan cargamentos destinados a puerto español, aunque procedan de otro puerto español, serán obligados a entrar en el de Gibraltar $[\ldots]^{, 35}$

Antes de lo sucedido con el patrullero francés, el Plus Ultra fue detenido la noche del 21 al 22 de diciembre de 1939. Se le escoltó a Gibraltar, donde fue retenido durante ocho horas ${ }^{36}$. Por supuesto, se le exigieron los pagos de los derechos de puerto y práctico. En esta detención se dan cuatro circunstancias fundamentales que afectan a todo este proceso. En primer lugar, la detención de un buque correo. Según las autoridades británicas el artículo $1^{\circ}$ de la XI Convención de La Haya no cubría los paquetes postales. Tampoco cubría artículos que no fueran genuinamente correo postal, como valores o billetes de banco ${ }^{37}$. Esto justificaría estas "innovaciones" en la práctica marítima. Cuando el sistema obligatorio de navicerts fue impuesto el 31 de julio de $1940^{38}$, todos los barcos debían llevar la carga navicertada. Aunque no llevaran carga, debían tener un navicert para el barco (ship navicert). Más adelante el Gobierno británico dejaría claro que el examen de la correspondencia es un derecho como beligerante que no admitía discusiones ${ }^{39}$. Esto provocaría muchas quejas por parte del Gobierno español, como veremos más adelante.

En segundo lugar, hay que mencionar las detenciones de barcos españoles entre puertos españoles que surcaban aguas jurisdiccionales con itinerario fijo. Este tipo de detenciones también provocaron bastante indignación y protestas por parte de las autoridades españolas. Según el Gobierno, dicha actitud era incomprensible, al estar rodeado de países aliados y al tratarse de rutas fijas entre puertos nacionales. Para el Gobierno británico, debían vigilarse aquellos puertos por los que el enemigo pudiera

\footnotetext{
${ }^{35}$ Dificultades para la navegación española en el Estrecho, 11 de mayo de 1940, AGA, Asuntos Exteriores, caja 7293.

${ }^{36}$ Remite copia Nota enviada a Foreign Office sobre detención "Plus Ultra", 15 de enero de 1940. AGA, Asuntos Exteriores, caja 6707.

${ }^{37}$ Informa sobre diferencias surgidas entre Estados Unidos y la Gran Bretaña por detención correo, 22 de enero de 1940, AGA, Asuntos Exteriores, caja 6707.

${ }^{38}$ Reprisals. German and Italian commerce restrictions, 31 de julio de 1940, TNA, Colonial Office: Colonies, General: Original Correspondence $(\mathrm{CO} 3323)$ expediente $1778 \quad 11$. https://discovery.nationalarchives.gov.uk/details/r/C4504762 (24/09/2020).

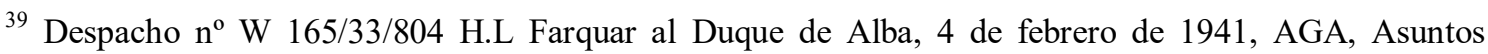
Exteriores, caja 7293.
} 
recibir mercancías. Es decir, España era considerada una zona de interés. La declaración de neutralidad no parecía haber convencido a las autoridades navales británicas.

En tercer lugar, Gibraltar como puerto de desvío. Durante toda la guerra, los barcos detenidos en la zona o al cruzar el Estrecho eran conducidos a Gibraltar, sin contar aquellos que eran despachados en alta mar. Paradójicamente, podía darse el caso contrario, como le pasó al Escolano ${ }^{40}$, obligado a detenerse en Freetown. Como el barco estaba dañado, se pretendía llevar a cabo las reparaciones correspondientes. Sin embargo, como todavía se encontraba en disposición de navegar, no se le permitió entrar en el puerto. Finalmente, acabó anclado a 11 millas al oeste del cabo de Sierra Leona. Esto dificultó enormemente las reparaciones, al encontrarse el barco en alta mar. Con el tiempo, este desvío se convertiría en todo un mecanismo rutinario por parte de las autoridades de control británicas, pero Gibraltar ya funcionaba como base de inspección de los barcos españoles desde 1939. Es interesante observar la respuesta del secretario de Estado británico (Secretary of State) ante las quejas por el control de contrabando en el Peñón:

I regret to state that His Majesty's Government are unable to waive their belligerant rights in accordance with the arrangement proposed by the Spanish Government, though they will continue to show such consideration as is possible to Spanish coastwise shipping. [...] I would remind you that no exercise of belligerant rights was recognized by His Majesty's Government during the Spanish Civil War, and that in searching British vessels at Gibraltar they were acting not under a concession made by the Spanish Government, but in exercise of their undoubted right to enforce upon their own nationals the provisions of the Non-Intervention Agreement ${ }^{41}$.

De esta forma el Gobierno británico dejaba claro a quién pertenecía Gibraltar y que seguiría inspeccionando los buques desde su puerto. Y le recordaba al Gobierno español las circunstancias de la guerra pasada. De hecho, los barcos españoles serían detenidos sobre todo en Gibraltar o sus aguas. Allí serán detenidos hasta recibir las pertinentes instrucciones de Londres ${ }^{42}$. El itinerario del barco era del todo indiferente,

\footnotetext{
${ }^{40}$ Despacho $n^{\circ}$ C 5923/1228/41 de Roger Makings a la Embajada de España en Londres, 30 de abril de 1940, AGA, Asuntos Exteriores caja 6707.

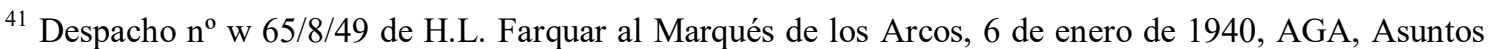
Exteriores caja 6707. Y también se encuentra en TNA, Colonial Office: Colonies, General: Original Correspondence (CO 323) expediente 170410.

${ }^{42}$ Este proceso se va dando de forma progresiva mediante las detenciones hasta que se transforme en un método oficial y obligatorio. Como muestra, la detención del Dómine, detenido con orden por escrito
} 
aun tratándose de navegación entre puertos de soberanía. Esta medida, claro, incluía barcos españoles o de cualquier otro país. Hasta ese momento, reconocían las autoridades españolas, muchos barcos eran examinados simplemente en alta mar, y no se obligaba al vapor a entrar en puerto si la documentación estaba en regla ${ }^{43}$. Por supuesto, esto suponía un agravamiento con respecto al proceder anterior.

Tampoco debemos olvidar la presencia alemana en torno al Peñón, donde los estudios conducidos por la inteligencia británica revelaron un sistema de espionaje extensivo por el espionaje alemán a ambos lados del estrecho ${ }^{44}$. De hecho:

[...] though German pressure to declare war and join the capture of Gibraltar was resisted, the Spanish government not only raised no obstacle to Axis operations but allowed its diplomatic consular, Service, Police and coastguard officials to give them active help. [Spain and Portugal were used] as bases for the surveillance of British shipping, for sabotage attacks on British shipping in Spanish ports and for espionage and sabotage operations against Gibraltar ${ }^{45}$.

Además, es relevante mencionar la operación BODDEN, respecto a la observación alemana del Estrecho ${ }^{46}$.

Continuando con nuestro barco, según se anotó en la documentación de a bordo del Plus Ultra, quedaba prohibido que se descargaran las mercancías en el puerto de Cádiz sin antes pasar por Gibraltar ${ }^{47}$. Vemos cómo se llegó a prohibir descargar en un puerto nacional. Esto supone otra forma de injerencia parcial de la soberanía. Evidentemente, las malas condiciones climáticas podían ocasionar graves retrasos. Este es el caso del Monte Castelo, el Cabo Torinana o el Río Francoli. En ocasiones no podían entrar en puerto y debían ser llevados a otra zona hasta que las dársenas estuvieran disponibles o el barco pudiera ser abordado. Detenciones que en principio podían resolverse con una visita en alta mar tuvieron que ser conducidas al Peñón por la

entregada al capitán, y llevado a Gibraltar el 26 de marzo. Este proceder, exactamente igual, se convertiría en norma a partir de mayo. Marqués de Bellpuig, Detención de la motonave Dómine en Gibraltar, 28 de marzo de 1940, AGA, Asuntos Exteriores caja 7679.

${ }^{43}$ Sobre la situación previa ver los dos documentos anteriores.

${ }^{44}$ Megan E. Cokely, "British counter-intelligence in Gibraltar: Deciphering Spanish neutrality during the Second World War”, International Journal of Iberian Studies 20 (2007) pp. 129-153.

${ }^{45}$ F.H. Hinsley; C.A.G. Simkins, British intelligence in the Second World War. Vol. IV. (Londres: HMSO, 1990), 148.

${ }^{46}$ A este respecto ver Manuel Ros Agudo, La Guerra Secreta de Franco (1939-1945) (Barcelona: Crítica, 2002), 219.

${ }^{47}$ El ministro de Asuntos Exteriores al embajador de España. 16 de marzo de 1940, AGA, Asuntos Exteriores caja 11338. 
situación atmosférica.

En junio de 1940, se comunicó que se habían dado instrucciones para asegurar que los barcos españoles enviados a la bahía estuvieran siempre bien anclados en su mitad oriental. Por su parte, los barcos españoles que voluntariamente anclaban en la mitad occidental no deben ser abordados por el control de contrabando. Además, los oficiales deben preguntar si había alguna queja, remitiéndola si la hubiera al oficial de embarque para su investigación. Finalmente, en ninguna circunstancia a los barcos españoles se les ordenaría o invitaría a salir de sus aguas territoriales. Al menos, según el gobierno de Su Majestad.

Hacia mayo de 1940 las detenciones de los barcos españoles que hacían navegación de cabotaje alrededor de la Península se llevaban a cabo "sistemáticamente" y con "harta frecuencia", según el Gobierno español ${ }^{48}$. Siguiendo su discurso, esta situación agravaba de manera alarmante el problema del abastecimiento de mercancías esenciales para el país. Desde principios de la guerra, y especialmente desde principios de 1940, las detenciones fueron continuadas. Por ejemplo, el ya mencionado Rio Francoli, detenido el 7 de enero, el 28 del mismo mes y luego el 5 y más tarde el 11 de febrero. Las quejas por las injerencias sobre las aguas territoriales se daban desde noviembre de 1939, y la censura de la correspondencia trazaría una línea similar en el tiempo.

En cuarto lugar, debemos mencionar el cobro de los derechos de puerto y práctico tras la entrada forzada a puerto para la inspección de control británica. Cuando un barco español era obligado a detenerse en Gibraltar, normalmente las autoridades británicas cobraban por el uso del puerto, como si se tratara de un barco que hubiera entrado voluntariamente. Los consignatarios pasaban los gastos a la Compañía Transmediterránea, que se encargaba del tráfico entre puertos de soberanía. Esta situación se veía agravada por tener que realizar el pago en libras. De hecho, el Instituto Español de Moneda Extrajera no pudo facilitar el cambio de divisas correspondiente. A partir del 18 de marzo estas facturas quedarían impagadas por parte de la Compañía Transmediterránea.

Según el Gobierno español, hacia abril de 1940 este desembolso continuado por

\footnotetext{
48 Detenciones barcos españoles por buques aliados. 7 de mayo de 1940, AGA, Asuntos Exteriores, caja 7293.
} 
los derechos había adquirido "el carácter de una contribución"49 e igual que se menciona en el documento anterior, se había vuelto "sistemático". Se solicitó que, de verse obligados a entrar en Gibraltar, se hiciera de forma gratuita, y que se aplicara dicha medida con carácter retroactivo, devolviendo el dinero desembolsado y anulando las facturas. El cobro de estos derechos generó muchas quejas del régimen franquista. Desde diciembre de 1939 podemos ver notas desde la embajada española a este respecto $^{50}$. ¿A qué se debía esta actitud? No parece que se tratara de ningún mecanismo de presión diplomática, ni que la deuda por el derecho de puerto pudiera usarse como herramienta económica. Lo relevante parece ser, más bien, la poca preocupación por las molestias ocasionadas por el control de contrabando durante estos primeros meses. Se suele considerar julio la fecha cuando los navicerts se convierten en obligatorios y las medidas del bloqueo se ven reforzadas. Sin embargo, a partir de mayo de 1940 existía ya todo un procedimiento de detenciones, que se mantendría de forma similar hasta el final de la guerra. Estas fechas coinciden con la evolución natural del conflicto.

\section{LAS DETENCIONES DE LOS BARCOS ESPAÑOLES}

Uno de los motivos de mayor fricción entre Gran Bretaña y España fue la presión e injerencia sobre las aguas jurisdiccionales, a pesar de una aparente mejora de las relaciones bilaterales en los primeros meses de la guerra, que serían poco más que un espejismo momentáneo ${ }^{51}$. En primer lugar, hay cinco vapores españoles que merecen nuestra atención, por lo acaecido en aguas territoriales españolas entre marzo y mayo de $1940^{52}$. El Delfín fue detenido el 31 de marzo, cuando iba de Río Martín a Santa Cruz de Tenerife, a dos millas y media de Sierra Bullones, en la costa del Marruecos español. Más tarde, el Monte Castelo fue interceptado el 15 de abril, cuando iba de Vigo a Ceuta,

\footnotetext{
${ }^{49}$ Compañia Transmediterránea al embajador de la Gran Bretaña en Madrid., 26 de abril de 1940, AGA, Asuntos Exteriores, Caja 7293.

${ }^{50}$ Ver, por ejemplo, nota de K.E. Roberson,8 de febrero de 1940, TNA, Colonial Office: Colonies, General: Original Correspondence (CO 323) expediente 170410.

${ }^{51}$ Fernández-Longoria Muñoz-Seca, Miguel. La diplomacia británica y el primer franquismo. Las relaciones hispano-británicas durante la Segunda Guerra Mundial. Tesis Doctoral, UNED, 2007, 130134. https://dialnet.unirioja.es/servlet/tesis?codigo=41375 (24/09/2020).

${ }^{52}$ Remite correspondencia con el FO sobre barcos españoles detenidos, 24 de octubre de 1940, AGA, Asuntos Exteriores, caja 6708.
} 
a dos millas y cuarto de Punta Lanchones. Dos días después lo mismo le sucedió al Darro, a milla y media de Punta Almina. Posteriormente, El Cabo la Plata fue detenido en viaje de Cádiz a Ceuta, a 1,9 millas de Punta Leona. Y finalmente, el Berga fue inspeccionado el 20 de mayo, en viaje de Ceuta a Río Martín, también dentro de las aguas jurisdiccionales españolas ${ }^{53}$. Llevaba productos petrolíferos de Tenerife. Su dueño estimó los perjuicios causados en 1.100 dólares. El otro documento referido al Berga afirmaba que a través del reporte de Gibraltar no se podía esclarecer si estaba en aguas españolas $^{54}$. El Gobierno británico respondió que no podía admitir cobro por daños ocasionados en el uso de sus derechos como beligerante, pero que se podía presentar el caso ante la Corte de Presas británica. La cuestión fue más allá. Los oficiales a bordo del Delfín tomaron varias fotografías del buque, de la tripulación y del cargamento. Por su parte, el caso del Cabo la Plata fue aún más grave: el destructor inglés que pretendía efectuar la detención llegó a insistir con dos disparos de cañón, para que el vapor español acudiera ante él para ser inspeccionado. Como el barco se encontraba en aguas jurisdiccionales españolas, el capitán no hizo caso, sin que el asunto pasara a mayores.

Según el Gobierno español, las violaciones de las aguas jurisdiccionales de su país por parte aliada se habían venido repitiendo con frecuencia, como pasaba a demostrar con estos $\operatorname{casos}^{55}$. En otra nota el gobierno franquista se queja debido a las "repetidas violaciones de las aguas jurisdiccionales" 56 por la Marina británica. De acuerdo con la versión británica de los hechos, tanto el Darro como el Delfín se encontraban a más de una milla fuera de aguas territoriales españolas. El Monte Castelo se encontraría aún más lejos. Según el Gobierno de Su Majestad, que los barcos fijaran su posición cuando se aproximaban a aguas territoriales españolas era ya cuestión de

\footnotetext{
${ }^{53}$ Despacho ${ }^{\circ} 147$ del Duque de Alba al Vizconde Halifax, 4 de julio de 1940, TNA, Foreign Office: Political Departments: General Correspondence from 1906-1966 (FO 371) expediente 24520. https://discovery.nationalarchives.gov.uk/details/r/C2782184 (24/09/2020).

${ }^{54}$ Del Ministry of Economic Warfare al Foreign Office, 22 de julio de 1940, TNA, Foreign Office: Political Departments: General Correspondence from 1906-1966 (FO 371) expediente 24520. https://discovery.nationalarchives.gov.uk/details/r/C2782184 (24/09/2020).

${ }^{55}$ Nota $^{\circ}{ }^{\circ} 116$ del Duque de Alba, 4 de junio de 1940, AGA, Asuntos Exteriores, caja 6708. (F6) Y también en: Nota $\mathrm{n}^{\circ} 116$, del Duque de Alba al Vizconde Halifax, 4 de junio de 1940, TNA, Foreign Office: Political Departments: General Correspondence from 1906-1966 (FO 371) expediente 24520. https://discovery.nationalarchives.gov.uk/details/r/C2782184 (24/09/2020).

${ }^{56}$ Nota $^{\circ} 50$ del Duque de Alba al Vizconde Halifax, 27 de marzo de 1940, TNA, Foreign Office: Political Departments: General Correspondence from 1906-1966 (FO 371) expediente 24520. https://discovery.nationalarchives.gov.uk/details/r/C2782184 (24/09/2020).
} 
rutina, y se tenía gran cuidado de no traspasarlas ${ }^{57}$. Sin embargo, en una nota confidencial del Almirantazgo de finales de junio se hace notar que las cuatro primeras detenciones ocurrieron a menos de tres millas de distancia de la costa española, confirmando las acusaciones iniciales del Gobierno español ${ }^{58}$. Es decir, se confirma que estas detenciones sí se produjeron dentro de las aguas territoriales españolas ${ }^{59}$. De igual modo, la versión británica respecto al Cabo la Plata es muy interesante. El vapor habría estado mirando hacia el Este desde su posición, al "limite" de las aguas territoriales. Para cuando se lanzaron los dos cañonazos, 20 minutos después de las primeras señales de aviso, ya se encontraría fuera de las aguas españolas. Finalmente, el barco fue conducido a Gibraltar por una de sus patrulleras.

Encontramos la misma explicación en la detención del Cabo San Sebastián en enero de 1940. De acuerdo con el Gobierno británico, el vapor debería haber sido abordado inmediatamente tras abandonar las aguas territoriales. No obstante, para ahorrar tiempo fue llamado para que se acercara. De este modo, el Cabo San Sebastián fue abordado fuera de las aguas jurisdiccionales. Según lo relatado en el informe, los oficiales británicos agradecieron al capitán por acercar la nave, dado que no les estaba permitido entrar en el límite de tres millas náuticas. No hubo protestas y se continuó la inspección sin ninguna sensación incómoda ${ }^{60}$. Algo parecido fue lo que le ocurrió al capitán del Darro, quien accedió a salir de las aguas jurisdiccionales para ser reconocido evitando así otros incidentes, de acuerdo con el Gobierno español. Parece que por parte de los dueños de los navíos se tenía orden de permanecer en aguas españolas en la medida de lo posible ${ }^{61}$. Por su parte, el Cabo San Antonio fue detenido por un yate

\footnotetext{
${ }^{57}$ Del Secretario de Estado al Duque de Alba, 22 de junio de 1940, AGA, Asuntos Exteriores, caja 7294.

${ }^{58}$ En otras notas, anteriores y posteriores, se incide en la versión que se trasladaría al gobierno español.

${ }^{59}$ Nota 2017/19 del Almirantazgo, 19 de junio de 1940, TNA, Foreign Office: Political Departments: General Correspondence from 1906-1966 (FO 371) expediente 24520. https://discovery.nationalarchives.gov.uk/details/r/C2782184 (24/09/2020). Cabe mencionar que el límite para las aguas territoriales era de casi cinco km; distancia que sería usada por el Gobierno británico para negar la injerencia en otros casos. En otros documentos del mismo expediente afirma que el Berga se encontraba a 4 millas de distancia al ser detenido.

${ }^{60}$ Del secretario de Estado al Duque de Alba, 22 de junio de 1940, AGA, Asuntos Exteriores, caja 7294. y también en Complaints regarding the boarding of Spanish ships, TNA, 18 de mayo de 1940, Foreign Office: Political Departments: General Correspondence from 1906-1966 (FO 371) expediente 24520. https://discovery.nationalarchives.gov.uk/details/r/C2782184 (24/09/2020).

${ }^{61}$ Contraband control base Gibraltar, 3 de junio de 1940, TNA, Foreign Office: Political Departments: General Correspondence from 1906-1966 (FO 371) expediente 24520. https://discovery.nationalarchives.gov.uk/details/r/C2782184 (24/09/2020).
} 
británico el 19 de enero. Al observar que se encontraban dentro de las aguas jurisdiccionales, ordenó al barco español que abandonara su posición para ser examinado $^{62}$. Igualmente, el Castillo Montealegre fue amenazado por el submarino Argo para que se dirigiera a Gibraltar tras salir de Las Palmas ${ }^{63}$. Es decir: en vez de detener directamente en las aguas territoriales españolas, lo que sería ilegal, se les forzaba salir de esas aguas territoriales para poder efectuar una inspección legal. Según el Gobierno británico, los barcos eran escoltados por las patrullas inglesas hasta una base o zona donde eran propiamente detenidos, ya en aguas territoriales británicas ${ }^{64}$.

Si estas prácticas no rompían la ley, al menos la bordeaban. De todas formas, parece que durante estos primeros meses las aguas territoriales españolas quedaron un tanto desdibujadas. También es importante mencionar una nota de mayo de 1940 donde el embajador español en París "manifiesta la conveniencia de que, al dar cuenta las autoridades navales o militares de una violación de aguas jurisdiccionales [...] señalen el hecho con la mayor precisión y lo más detalladamente posible, con objeto de facilitar la eficacia de la reclamación diplomática que haya de efectuarse" ${ }^{, 65}$. Curiosamente, en algunos documentos se recalca que el derecho del Gobierno de Su Majestad a examinar barcos en busca de contrabando existe fuera de las aguas territoriales ${ }^{66}$.

De todas formas, estos casos no fueron los únicos, como demuestra la detención del Río Francoli a finales de enero, interceptado según el Gobierno español a milla y media del puerto de Ceuta ${ }^{67}$. Según el Gobierno británico, "Aunque ahora no se puede establecer la posición exacta en la que [la detención] tuvo lugar, no estaba dentro de las aguas territoriales españolas. Los navíos de embarque hacen que sea una rutina fijar su

\footnotetext{
${ }^{62}$ Embajada de España en Londres, 11 de abril de 1940, TNA, Foreign Office: Political Departments: General Correspondence from 1906-1966 (FO 371) expediente 24520. https://discovery.nationalarchives.gov.uk/details/r/C2782184 (24/09/2020).

63 Sobre detención buque español "Castillo Montealegre”, AGA, 25 de marzo de 1940, Asuntos Exteriores, caja 11338.

${ }^{64}$ Correspondence between His Majesty's Government in the United Kingdom and the Government of the United States regarding the Censorship of Mails, 16 de enero de 1940, AGA, Asuntos Exteriores, caja 7278.

65 Sobre violación nuestra soberanía. 22 de mayo de 1940, Archivo General del Ministerio de Asuntos Exteriores y Cooperación (AMAE), Archivo renovado (R), caja 1182, expediente 132.

${ }^{66}$ Por ejemplo, Despacho $n^{\circ}$ w 7062/5582/49 del Foreign Office al Marques de los Arcos, 7 de mayo de 1940, AGA, Asuntos Exteriores, caja 7293. (A1S4F21)

${ }^{67}$ Complains regarding the boarding of Spanish ships 18 de mayo de 1940, TNA, Foreign Office: Political Departments: General Correspondence from 1906-1966 (FO 371) expediente 24520. https://discovery.nationalarchives.gov.uk/details/r/C2782184 (24/09/2020).
} 
posición al acercarse a aguas territoriales, y tienen mucho cuidado de no entrar en ellas". El mismo argumento es usado por el Gobierno británico en cuanto a la detención del Castillo Daroca; no se puede saber la posición exacta, pero no fue dentro de sus aguas territoriales $^{68}$.

Antes de subir a bordo, se interrogó a la embarcación mediante morse, para luego subir a bordo un teniente de navío acompañado de hombres armados. Tras examinar la documentación, se autorizó al navío a continuar su viaje. Y es que el exceso de celo británico no estaba necesariamente injustificado. España era un neutral muy "particular" que colaboró activamente con los alemanes, también en el ámbito naval, tal y como fue señalado en las páginas anteriores.

Estas interpretaciones un tanto forzadas de la ley no fueron las únicas, como veremos en el caso del control de la correspondencia. Otro caso es el del vapor Cobetas, al que, según el Gobierno español, se le ordenó salir de aguas españolas cuando se encontraba cerca de Punta Europa en octubre de 1939. De acuerdo con un informe del Gobierno británico, la inspección se realizó fuera de la jurisdicción española ${ }^{69}$. También es interesante el caso del Monte Castelo. Se le ordenó entrar en Gibraltar, pero, debido al mal tiempo, arribó frente a la desembocadura del río Palomares, en aguas españolas, donde fue reconocido por el control inglés ${ }^{70}$. El mismo día era detenido frente a Punta Europa el Cabo Toriñana, al cual se indicó que fondeara en Punta Mayorga, en aguas españolas, en calidad de barco detenido, para proceder a su inspección. Debido al mal tiempo y al número de barcos, la inspección fue retrasada hasta el día 6 .

En cualquier caso, esta práctica nunca desembocó en el uso extremo de la fuerza. Lo más que podemos ver es algún disparo de aviso. Otro ejemplo es lo ocurrido con el

\footnotetext{
${ }^{68}$ Despacho $\mathrm{n}^{\circ}$ M.09207/40 del Secretariado de Estado al Almirantazgo, 6 de junio de 1940, TNA, Foreign Office: Political Departments: General Correspondence from 1906-1966 (FO 371) expediente 24520.. https://discovery.nationalarchives.gov.uk/details/r/C2782184 (24/09/2020).

${ }^{69}$ Despacho n ${ }^{\circ}$ 1232/24 del Oficial de Bandera al mando de la Estación del Atlántico Norte (F.O.C. North Atlantic Station) al Almirantazgo, 25 de diciembre de 1939, TNA, Foreign Office: Political Departments: General Correspondence from 1906-1966 (FO 371) expediente 24520. https://discovery.nationalarchives.gov.uk/details/r/C2782184 (24/09/2020).

${ }^{70}$ Complains regarding the boarding of Spanish ships 18 de mayo de 1940, TNA, Foreign Office: Political Departments: General Correspondence from 1906-1966 (FO 371) expediente 24520. https://discovery.nationalarchives.gov.uk/details/r/C2782184 (24/09/2020). Según el Gobierno británico, el barco arribó en la parte noroeste de la Bahía de Gibraltar. Lo mismo respecto al Cabo Torinana, que ancló en el fondeadero comercial.
} 
Castillo Maqueda en marzo de $1940^{71}$. Este se negó a salir de las aguas jurisdiccionales, continuando sin más problemas hasta que un destructor inglés (ya fuera de las aguas jurisdiccionales) le ordenó ir hacia Gibraltar.

También es necesario señalar que se dieron casos de violaciones de aguas territoriales que involucraron barcos de otras nacionalidades. Esta problemática la podemos ver con el vapor sueco Escandinavia en diciembre de 1939, detenido a milla y media del Puerto de Algeciras para ser conducido a Gibraltar. Otro caso relevante sucedido en el mismo mes es la persecución en la costa de Rota del barco alemán Glücksburg por el buque británico HMS Wishart ${ }^{72}$, que llegó a penetrar en aguas territoriales españolas, liberando una barcaza con, según los españoles, una ametralladora a bordo. El capitán del Wishart insistió en sus declaraciones que no se coaccionó al barco alemán ni llevaba en la barcaza una ametralladora. En efecto, se violaron las aguas territoriales, pero fue en orden de "salvar la vida",73.

Como hemos visto, las injerencias sobre las aguas territoriales españolas se dieron desde el mismo comienzo de la guerra. Y en junio de 1940, las quejas del Gobierno español respecto a estas violaciones fueron aún mayores, afirmando que "lejos de disminuir las violaciones de las aguas jurisdiccionales [...] se han seguido repitiendo aquellas con frecuencia" 74 . Como respuesta a esto, el general Dudley North recalcó en una nota que, a pesar de las quejas diplomáticas, las relaciones entre los capitanes y el contrabando habían sido siempre cordiales; que no se había presentado ninguna queja y, además, recalcó que en ninguna circunstancia se ordenó o invitó a abandonar las aguas territoriales españolas, ${ }^{75}$ argumento que, como hemos visto, no es cierto.

\footnotetext{
${ }^{71}$ Ficha de información de buques mercantes, n/r $\mathrm{r}^{\mathrm{a}}$ 106-R 3 de abril de 1940, AGA, Asuntos Exteriores, Sección de Marina, caja 23637.

72 Incident in Spanish territorial waters involving a German ship and a torpedo boat of a British nationality, 9 de febrero de 1940, TNA, Foreign Office: Political Departments: General Correspondence

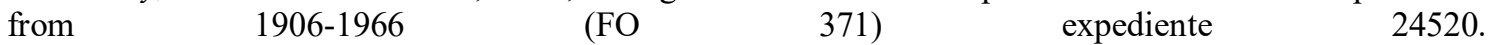
https://discovery.nationalarchives.gov.uk/details/r/C2782184 (24/09/2020).

73 Despacho no M.03795/40 del Almirantazgo, 1 de mayo de 1940, TNA, Foreign Office: Political Departments: General Correspondence from 1906-1966 (FO 371) expediente 24520. https://discovery.nationalarchives.gov.uk/details/r/C2782184 (24/09/2020)

${ }^{74}$ Nota n ${ }^{\text {o }} 116$ del Duque de Alba, 4 de junio de 1940, AGA, Asuntos Exteriores, caja 6708. Y también en: Nota ${ }^{\circ} 116$, del Duque de Alba al Vizconde Halifax, 4 de junio de 1940, TNA, Foreign Office: Political Departments: General Correspondence from 1906-1966 (FO 371) expediente 24520. https://discovery.nationalarchives.gov.uk/details/r/C2782184 (24/09/2020).

75 Complains regarding the boarding of Spanish ships 18 de mayo de 1940, TNA, Foreign Office: Political Departments: General Correspondence from 1906-1966 (FO 371) expediente 24520. https://discovery.nationalarchives.gov.uk/details/r/C2782184 (24/09/2020). 
Otro caso interesante es el del Badalona, un petrolero que fue detenido mientras acarreaba un cargamento de combustible para la Armada española. El barco pertenecía a una compañía estatal, lo cual hace del asunto un tema aún más delicado. Algo parecido pasaba con el Ciudad de Algeciras, vapor correo con servicio entre Ceuta y Algeciras ${ }^{76}$, que frecuentemente llevaba a bordo tropas españolas. Según el Gobierno británico, este hecho no afectaba en absoluto su estatus. Incluso llegó a decir que personas que regresan a Alemania para cumplir con sus obligaciones militares podían ser transportadas por esta ruta ${ }^{77}$. Según el Gobierno británico, el hecho de transportar fuerzas militares no era razón para no ejercer el derecho de visita ${ }^{78}$. No obstante, el hecho de detener barcos estatales, así como barcos donde viajaban tropas del Ejército, suponía un nuevo matiz a la hora de entender la injerencia británica, y una nueva apreciación de la opinión del MEW hacia la España franquista. Aquí podemos apreciar otras formas en las que se presenta la interferencia del tráfico marítimo español. Incluso la Armada española podía verse afectada. En la misma nota, se hace referencia al reciente War Trade Agreement (Acuerdo de Comercio de Guerra) esperando que llevara a una reducción de todas estas dificultades. Igualmente, el Río Francoli fue detenido el 5 febrero por un destructor inglés ${ }^{79}$ a seis millas al norte de Ceuta. Este vapor transportaba trigo en base al Tratado Comercial firmado recientemente con Francia, en un viaje requisado por el Estado con esa finalidad. Podemos ver cómo dichos acuerdos comerciales, aunque permitieron adquirir productos vitales para la economía española, no supusieron un cambio en el mecanismo de control del contrabando.

La incautación y censura de la correspondencia fue motivo de muchas fricciones y quejas por parte del Gobierno español, incluso antes del sistema de sustitución de la correspondencia. Con el tiempo, el control de la correspondencia a través de Gibraltar fue un protocolo a seguir por las autoridades británicas. En estos primeros meses de “neutralidad" española, la incautación de la correspondencia por las autoridades franco-

\footnotetext{
${ }^{76}$ Nota n$^{\text {o }} 57$ al Vizconde de Halifax, 29 de marzo de 1940, AGA, Asuntos Exteriores, caja 7293.

${ }^{77}$ Despacho ${ }^{\circ}$ w 7062/5582/49 al Marqués de los Arcos, 7 de mayo de 1940, AGA, Asuntos Exteriores, caja 7293.

78 Transmite contestación del FO a las protestas sobre detención vapores "Ciudad de Algeciras" y “Ciudad de Sevilla” 9 de mayo de 1940, AGA, Sección de Marina, caja 23637.

${ }^{79}$ Nota $\mathrm{n}^{\circ} 51$ del Duque de Alba, 28 de marzo de 1940, TNA, Foreign Office: Political Departments: General Correspondence from 1906-1966 (FO 371) expediente 24520. https://discovery.nationalarchives.gov.uk/details/r/C2782184 (24/09/2020). Y también en Sobre detención buques Compañía Transmediterránea, 12 de marzo de 1940, AGA, Asuntos Exteriores, caja 11338.
} 
británicas también tuvo un gran peso. Las detenciones galas y el consiguiente desvío a puertos franceses eran también destacables. A finales de marzo se mostró el interés que tenía el Gobierno español para que los buques del servicio regular con Canarias o las posesiones de Guinea no fueran conducidos a estos puertos. Lo mismo sucedía con la navegación de cabotaje ${ }^{80}$. Los vapores correo eran interceptados y sus cartas abiertas o censuradas. Las molestias que este sistema llegó a causar al tráfico postal no eran pocas $^{81}$. Para toda Europa se estableció un control de la correspondencia ${ }^{82}$.

Fue a partir de octubre de 1939 cuando se endurecieron las medidas de control en Gibraltar con la llegada del personal de censura bajo el mando de un censor jefe ${ }^{83}$. Todos los correos destinados a Europa fueron sometidos a un examen completo. El hecho de llevar la carga totalmente revisada y poseer un ship navicert no eximía de la censura de la correspondencia. De hecho, los navicerts no eran otorgados a los capitanes que llevaran correo a menos que el capitán se comprometiera a dejar el correo en algunas de las bases de control de la correspondencia ${ }^{84}$, aunque en teoría España no estaría incluido dentro de estas medidas, probablemente por la existencia de los controles en el Peñón; en cualquier caso, España sí acabó viéndose obligada a entregar el correo a bordo a las autoridades de control de la correspondencia. En la misma nota se afirma que el trato concedido a los buques españoles era "excepcionalmente favorable" ${ }^{, 85}$ debido a ello, aunque la nota se refiere más bien a las bases de Freetown,

\footnotetext{
${ }^{80}$ Referente detención vapor Francoli. 27 de marzo de 1940, AGA, Asuntos Exteriores, caja 11338.

${ }^{81}$ Hacia febrero de 1941 Gran Bretaña admitió que las deviaciones a las bases de inspección en la ruta del sur son considerables. Por lo tanto, si los consignatarios no podían mandar sus barcos vía Trinidad, se les ofrece la posibilidad de usar la American Export Line Service a Bermuda. Así, la correspondencia iría en los buques de la Grace Line a cargo del Tesoro Británico. Despacho no w165/33/804 H.L. Farquar al Duque de Alba, 4 de febrero de 1941, AGA, Asuntos Exteriores, caja 7293. Una vez puesta en marcha la línea regular con Sudamérica, los buques seguirían siendo detenidos por las autoridades de control franco británicas. Ver Sobre detención buque Compañia Transmediterránea, 12 de marzo de 1940, AGA, Asuntos Exteriores, caja 11338.

${ }^{82}$ Cypher Telegram Circular from the Secretary of State for the Colonies to all Colonial Goverments, 24 de octubre de 1939, TNA, Colonial Office: Colonies, General: Original Correspondence (CO 323) expediente 1681 4. https://discovery.nationalarchives.gov.uk/details/r/C4503114 (24/09/2020).

${ }^{83}$ Instructions for examinations of mails, 26 de octubre de 1939, TNA, ADM (Records of the Admiralty, Naval Forces, Royal Marines, Coastguard, and related bodies) 199 Admiralty: War History Cases and Papers, Second World War. https://discovery.nationalarchives.gov.uk/details/r/C4122474 (24/09/2020).

84“"The compulsory ship navicert system, provisions for mails", TNA, ADM 199 Admiralty: War History Cases and Papers, Second World War. https://discovery.nationalarchives.gov.uk/details/r/C4122474 $(24 / 09 / 2020)$.

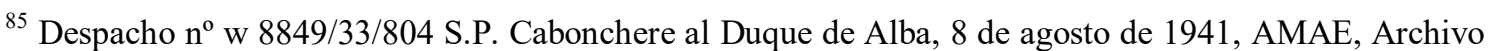
renovado (R) caja 1182, expediente 132.
} 
Bermuda y Trinidad. De acuerdo con el reglamento vigente, todos los barcos que transportaran correo eran obligados a ir a una base de control, excepto, en teoría, el tráfico costero español y portugués, así como el tráfico entre ambos países y sus islas atlánticas y Marruecos. Como vemos, esta arbitrariedad no redundaría en la ausencia de la censura. Además, parecía condicionarse al buen comportamiento de los españoles. De hecho, Janet Cohen afirma que "the contraband and the irregularities in the ships navicerts which were discovered during the searches meant that inspections had to be more comprehensive." 86

Veamos un ejemplo. El vapor Escolano fue detenido por un destructor francés el 24 de noviembre de 1939. Realizaba la travesía de Las Palmas a Cádiz. El oficial francés tachó dos líneas de los acaecimientos estampados en la singladura. Estas líneas rezaban haber visto un periscopio a estribor que luego desapareció. En el mismo barco fue detenido un súbdito alemán, que había llegado a la Península en junio de 1939.

Más adelante, el 6 de febrero, fue detenido el Ciudad de Sevilla, en viaje desde Canarias a Barcelona. El buque entró forzosamente en Gibraltar. Se inspeccionó varias sacas de correspondencia y se sacó una de certificados. Esta correspondencia fue devuelta al barco, el cual zarpó al día siguiente. Según las autoridades de Su Majestad, se recibió un informe según el cual el vapor transportaba vino para Alemania. Un paquete de correspondencia alemán fue llevado a tierra. Las autoridades británicas insistieron en que ningún correo fue declarado al patrullero. Un informe posterior aseguró que el Ciudad de Sevilla tenía contrabando a bordo ${ }^{87}$. Este barco fue el primer barco cuya correspondencia fue interceptada en Gibraltar. Al menos, era la primera vez que el cónsul general de España tuvo noticia de ello ${ }^{88}$.

Otro ejemplo interesante es la nueva detención del Río Francoli. Viajaba de Fernando Póo a la Península con escala en Las Palmas. El 7 de enero fue interceptado

\footnotetext{
${ }^{86}$ Janet Cohen. The Ministry of Eonomic Warfare and Britain's conduct of Economic Warfare, 1939-1945 (Tesis doctoral, King's Collegue, 2001) https://kclpure.kcl.ac.uk/portal/en/theses/the-ministry-ofeconomic-warfare-and-britains-conduct-of-economic-warfare-19391945(d51b0c17-882c-420c-97b13ffead720c43).html 164 (24/09/2020).

${ }^{87}$ Complains regarding the boarding of Spanish ships 18 de mayo de 1940, TNA, Foreign Office: Political Departments: General Correspondence from 1906-1966 (FO 371) expediente 24520. https://discovery.nationalarchives.gov.uk/details/r/C2782184 (24/09/2020).

${ }^{88}$ Detención de barcos españoles por los ingleses, AGA, 9 de febrero de 1940, Asuntos Exteriores, caja 7293.
} 
por un crucero francés a 200 millas al norte de Dakar y conducido a Casablanca ${ }^{89}$. Se revisó toda la correspondencia y se requisó 151 cartas ordinarias y 24 certificadas. Los despachos fueron devueltos intactos. Fue liberado el día 17. Además de correspondencia, transportaba cacao de Guinea. Según las autoridades españolas, nada justificaba la detención. Se argumentaba también que al tener carácter de buque correo, este se veía obligado a tener itinerario fijo. También dicho carácter le impedía tener escalas imprevistas. De igual modo, respecto a la detención del Monte Sollube se informó de que, para aligerar cualquier retraso en el futuro, se debía enviar directamente los documentos de los buques a la Comisión de Control de Contrabando. El objetivo era que se recibieran antes de que los buques llegaran al puerto donde serían examinados ${ }^{90}$.

En agosto de 1940 el sistema de navicerts se haría obligatorio. Esto significaba que el bloqueo marítimo alcanzaría su forma más desarrollada. A partir del verano, todos los barcos debían llevar un navicert. De no llevarlo, serían objeto de presa, lo cual convirtió a los certificados navales en absolutamente obligatorios para navegar por el Atlántico. Ya en septiembre aparecían varias quejas sobre la detención de buques que no llevasen los certificados, y sobre cómo las casas armadoras no podían conseguir uno si no tenían toda la carga cubierta por estos certificados. Además, en un telegrama Lord Lothian afirma que, dado los problemas con las compañías (ya que nunca encontraban problemas para navegar sin navicerts) y barcos que pasaban por Gibraltar, así como los barcos con cargas mixtas para puertos atlánticos portugueses y españoles, la detención de algunos barcos podría ser para el Gobierno británico una verdadera arma; sin el arma de las detenciones, el Gobierno británico carecía de poder ${ }^{91}$. Sin embargo, para las colonias españolas (incluyendo a las Islas Canarias) se concedería un período de gracia o transición de un modelo a otro. Esto nos revela la especial importancia que revestía al tráfico por las Islas.

En la práctica, esto se traducía en que no hacían falta los navicerts, siendo suficiente con los certificados de origen como hasta ese momento. Además, podía

\footnotetext{
89 Sobre detención vapor español "Francoli”, 29 de febrero de 1940, AGA, Asuntos Exteriores, caja 11338.

${ }^{90}$ El Duque de Alba a Azeta Investment Trust Ltd., 27 de octubre de 1939, AGA, Asuntos Exteriores, caja 7679 .

91 Extract from telegram from Lord Lothian, Washington, 28 de junio de 1940, TNA, Foreign Office: Ministry of Economic Warfare and successors: Records (837) expediente 719. https://discovery.nationalarchives.gov.uk/details/r/C256913 (24/09/2020).
} 
aceptarse los conocimientos de embarque del cónsul correspondiente, o los conocimientos generales de embarque para pequeñas partidas. Sin embargo, ya desde agosto se insistía en pedir los navicerts con la antelación necesaria, la cual a veces podía llegar a preceder a la fecha de embarque ${ }^{92}$. De esta situación podemos deducir la importancia que tenía el control marítimo de las colonias españolas, dada su especificidad. Y, por tanto, la importancia del tráfico marítimo en esa zona del Atlántico. También podemos apreciar la especificidad canaria en la petición del Duque de Alba al Gobierno británico de excluir del control de contrabando a los barcos que navegaran entre Canarias y la Península, así como a los pequeños vapores que cruzaban el Estrecho. Y es que en lo que respecta a las comunicaciones marítimas la zona atlántica canaria revestiría de una importancia similar a la zona del estrecho de Gibraltar $^{93}$, al menos en el caso Español. Finalmente, toda esta situación nos revela la intención de Gran Bretaña de permitir a España adaptarse a este nuevo sistema, al mismo tiempo que cerraba el puño en torno a los mares. El imperio británico vendría a consolidar una práctica que se venía dando durante esta etapa. Así, agosto de 1940 cierra el período que analizamos, con la extensión y puesta en marcha del sistema de certificados navales. Este sistema también funcionó con ciertas especificidades para Canarias y las posesiones coloniales en Marruecos.

\section{CONCLUSIONES}

En primer lugar, podemos concluir que mayo de 1940 fue la fecha en torno a la cual se vertebró un cambio en el procedimiento de las detenciones navales de esta área del Atlántico. A partir de este momento, lo que habían sido inspecciones en alta mar se convirtieron en el paso obligatorio por Gibraltar. De hecho, que los barcos detenidos en Gibraltar tuvieran que esperar respuesta de Londres no es sino el precedente directo del sistema de navicerts obligatorios, que sustituyeron a los viejos navicerts " $Z$ ”. Gibraltar

\footnotetext{
92 Asuntos Económicos, Madrid, 2 de septiembre de 1940, AMAE, Archivo Renovado (R) caja 2251, expediente 64 .

${ }^{93}$ Despacho ${ }^{\circ}$ 4831, 29 de marzo de 1940, TNA, Foreign Office: Political Departments: General Correspondence from 1906-1966 (FO 371) expediente 24520. https://discovery.nationalarchives.gov.uk/details/r/C2782184 (24/09/2020). Curiosamente, en esta misma nota se hace referencia a que el Duque no estaba muy familiarizado en lo referente a estos casos sobre barcos, y que olvidó firmar una de las notas.
} 
se configuró como puerto de desvío desde el principio. Estamos ante un control marítimo totalmente centralizado. $\mathrm{Y}$ es que estos meses serían de vital importancia para la actividad del FO en España, debido al tráfico comercial alemán. Tras la capitulación francesa precisamente en mayo, estos cambios se vendrían a consolidar y a desarrollarse a gran escala; este contexto cambiante explica en su medida todo este proceso de detenciones y sistemas de control.

En segundo lugar, hemos podido determinar cómo la injerencia británica se dio de tres formas: el control de la correspondencia, el desvío y detención de la navegación y la presión sobre las aguas jurisdiccionales. Además, el bloqueo sirvió a ciertos fines de inteligencia desde el principio. Esta situación se da en el cambiante contexto al que nos enfrentamos, donde el gobierno británico tenía sospechas, indicios y conocimiento de parte de la colaboración naval hispano-germana, lo que por supuesto afectaría al desarrollo del control naval en la zona. El doble juego de España afectaría a la percepción británica y su actuación sobre ella.

En tercer lugar, observamos que no había excepciones según el tipo de barco o su circunstancia; ninguno escapaba a la inspección naval. Los acuerdos comerciales que se firman entre ambos países y con Francia no parecen tener influencia en el proceso de las detenciones. A pesar de que se dan acuerdos puntuales, flexibilizando ciertas medidas, en la práctica no existió mucha diferencia con el resto de las zonas, debido a la desconfianza hacia el gobierno franquista. En cuarto lugar, las detenciones fueron usadas como arma política, para hacer extensivo el sistema del navicert ${ }^{94}$, para fiscalizar a España en un momento donde las estructuras del control de contrabando no estaban bien definidas, y como herramienta para definir una política de injerencia que no dañase hasta un punto irreparable la situación con el gobierno franquista. Todo esto nos habla de la desconfianza de Gran Bretaña hacia España; desde los primeros meses de la guerra podemos ver detenciones e inspecciones de barcos españoles.

En quinto lugar, la injerencia británica sobre las aguas territoriales nos habla de la extraordinaria debilidad española, y de cómo España quedaría inserta desde el comienzo en un sistema que reguló totalmente su tráfico marítimo, que era vital para la economía española de posguerra. Lo cual nos puede ayudar a entender mejor el porqué

\footnotetext{
94 LOTHIAN: "Extract from telegram from Lord Lothian, Washington, 28th june, 1940" (Washington, 28 de junio de 1940) The National Archives (TNA) Ministry of Economic Warfare and successors: Records (FO 837) exp. 719, https://discovery.nationalarchives.gov.uk/details/r/C256913 (24/09/2020).
} 
de la no entrada de Franco en el conflicto; hasta qué punto España estaba subyugada y era dependiente del viejo imperio británico.

\section{BIBLIOGRAFÍA}

Catalan, Jordi. La economía española y la segunda guerra mundial. Barcelona: Editorial Ariel, 1995.

Cohen, Janet. The Ministry of Economic Warfare and Britain's conduct of Economic Warfare, 1939-1945. Tesis Doctoral, King's Collegue, Londres, 2001. https://kclpure.kcl.ac.uk/portal/en/theses/the-ministry-of-economic-warfare-andbritains-conduct-of-economic-warfare-19391945(d51b0c17-882c-420c-97b13 ffead720c43).html

Cokely, Megan E. "British counter-intelligence in Gibraltar: Deciphering Spanish neutrality during the Second World War", International Journal of Iberian Studies 20 (2007) pp. 129-153.

Díaz Benítez, Juan José. "El anteproyecto de flota de 1938 y la no beligerancia española durante la Segunda Guerra Mundial", Ayer. Revista de Historia Contemporánea, núm. 49 (2003): 271-289.

Díaz Benítez, Juan José. "The Spanish support for the Third Reich in the Second World War: new considerations about the Etappenorganisation", The International Journal of Maritime History 28, núm. 3 (2016): 513-531, doi: $10.1177 / 0843871416647347$.

Díaz Benítez, Juan José. "The Etappe Kanaren: A case study about the secret supply of the German Navy in Spain during the Second World War", The International Journal of Maritime History 30, núm. 3 (2018): 472-487, doi: 10.1080/00253359.2018.1487676.

Díaz Benítez, Juan José. "German supply ships and blockade runners from the Canary Islands in the Second World War", The Mariner's Mirror 104, núm. 3 (2018): 318-329, doi: 10.1080/00253359.2018.1487676.

Díaz Benítez, Juan José. "El ataque contra el buque alemán Corrientes en el Puerto de la Luz en mayo de 1940", en XX Coloquio de Historia Canario Americana (2012), coord. por Elena Acosta Guerrero, 1161-1170. Las Palmas de Gran Canaria: Cabildo de Gran 2014. http://coloquioscanariasamerica.casadecolon.com/index.php/CHCA/article/view/ $\underline{9242}$

Doussinague, José María. España tenía razón. Madrid: Espasa Calpe, 1949.

Fernández-Longoria Muñoz-Seca, Miguel. La diplomacia británica y el primer franquismo. Las relaciones hispano-británicas durante la Segunda Guerra Mundial. Tesis Doctoral, UNED, 2007. https://dialnet.unirioja.es/servlet/tesis?codigo $=41375$ (24/09/2020).

García Pérez, Rafael. Franquismo y Tercer Reich: las relaciones económicas hispanoalemanas durante la Segunda Guerra Mundial. Madrid: Centro de Estudios Constitucionales, 1994.

Gilmour, John. Sweden, the Swastika and Stalin. The Swedish Expreience in the Second World War. Edinburgh: Edinburgh University Press, 2011.

F.H. Hinsley; C.A.G. Simkins, British intelligence in the Second World War. Vol. IV. Londres: HMSO, 1990. 
Grandío Seoane, Emilio. A Balancing Act: British Intelligence in Spain during the Second World War. Brighton: Sussex Academic Press, 2017.

Grandío Seoane, Emilio. No sólo wolframio. Galicia, campo de juego de las redes de inteligencia durante la Segunda Guerra Mundial. En Revista Universitaria de Historia Militar, (2015) pp. 101-117.

Henri Michel, La Segunda Guerra Mundial. Tomo I. Los éxitos del Eje. $2^{\mathrm{a}}$ Ed. Madrid: Akal, 1990.

Hernández Sandoica, Elena y Enrique Moradiellos, "Spain and the Second World War, 1939-1945", en European neutrals and non-belligerents during the Second World War, ed. por Neville Wylie, 241-267. Cambridge: Cambridge University Press, 2002.

Leitz, Christian. Nazi Germany and Neutral Europe during the Second World War. Manchester: Manchester University Press, 2000.

Manuel Ros Agudo, La Guerra Secreta de Franco (1939-1945) Barcelona: Crítica, 2002.

Milward, Alan S. Historia económica mundial siglo XX. La Segunda Guerra Mundial 1939-1945. Barcelona: Crítica, 1986.

Moradiellos, Enrique. Franco frente a Churchill: España y Gran Bretaña en la Segunda Guerra Mundial (1939-1945). Barcelona: Ediciones Península, 2005.

Morales Lezcano, Víctor. Historia de la no beligerancia española durante la Segunda Guerra Mundial. Las Palmas de Gran Canaria: Mancomunidad de Cabildos de Las Palmas, 1980.

O'Halpin, Eunan. "Irish Neutrality in the Second World War", en European neutrals and non-belligerents during the Second World War, ed. por Neville Wylie, 283303. Cambridge: Cambridge University Press, 2002.

Pike, David Wingeate. Franco y el Eje Roma-Berlín-Tokio. Madrid: Alianza Editorial, 2010.

Ponce Alberca, Julio. "La Guerra Civil y el Peñón de Gibraltar" en Historia Contemporánea, 41 (2010) pp. 321-343.

Ponce Alberca, Julio. "Espionaje en Gibraltar y su Campo (1936-1945)" en Revista Universitaria de Historia Militar, (2015) pp. 35-54.

Ros Agudo, Manuel. La guerra secreta de Franco (1939-1945). Barcelona: Editorial Crítica, 2002.

Rosas, Fernando. "Portuguese neutrality in the Second World War", en European neutrals and non-belligerents during the Second World War, ed. por Neville Wylie, 268-282. Cambridge: Cambridge University Press, 2002.

Serrano Suñer, Ramón. Entre Hendaya y Gibraltar. Madrid: Ediciones y Publicaciones Españolas, 1947.

Suárez Fernández, Luis. España, Franco y la Segunda Guerra Mundial. Madrid: Editorial Actas, 1997.

Smyth, Denis. Diplomacy and strategy of survival. British policy and Franco's Spain, 1940-41. Cambridge: Cambridge University Press, 1986.

Thomàs, Joan Maria. Roosevelt y Franco. De la guerra civil española a Pearl Harbor. Barcelona: Edhasa, 2007.

Thomàs, Joan Maria. La batalla del wolframio. Estados Unidos y España. De Pearl Harbor a la Guerra Fría (1941-1947). Madrid: Ediciones Cátedra, 2010.

Tusell, Javier. Franco, España y la Segunda Guerra Mundial. Madrid: Ediciones Temas de Hoy, 1995. 
Teodoro Fidel Santana Nelson y Juan José Díaz Benítez

El control naval aliado entre Canarias y la Península durante la Segunda Guerra Mundial (septiembre de 1939-junio de 1940)

Viñas, Ángel. Sobornos: De cómo Churchill y March compraron a los generales de Franco. Barcelona: Crítica, 2016.

Wylie, Neville. Britain, Switzerland and the Second World War. Oxford: Oxford University Press, 2003. 